Journal Of Al Azhar University Engineering Sector

Vol. 11, No. 39, April 2016, 435-446

\title{
ARTIFICIAL NEURAL NETWORK MODEL FOR FORECASTING CONCRETE COMPRESSIVE STRENGTH AND SLUMP IN EGYPT
}

\author{
Ashraf Henigal $^{1}$, Emad Elbeltgai ${ }^{2,}$ Mostafa Eldwiny $^{3 *}$, Mohamed Serry ${ }^{4}$ \\ ${ }^{1}$ Suez University, Suez, Egypt \\ ${ }^{2}$ Structural Eng. Dept., Mansoura University, Mansoura , Egypt, \\ ${ }^{3}$ Graduate Student, Civil Construction. Dept., Beni-Suief University, \\ ${ }^{4}$ Head of the Consulting Engineering Sector, Arab Contractors, Egypt.
}

\begin{abstract}
Slump and compressive strength of concrete are commonly used criteria in evaluating fresh and hardened concrete. Accordingly, prediction of such criteria is important for the quality assurance of the produced concrete. In this paper, a Neural Network (NN) model is developed to predict concrete compressive strength and slump in Egypt. The Artificial Neural Network (ANN) model is developed, trained and tested using 1000 different concrete mixes gathered from different batch plants distributed all over the Arab Republic of Egypt. Important parameters that have noticeable effect on the compressive strength and slump are identified and used as the inputs for the ANNs model. The developed model can be used either to predict the compressive strength and slump for a given mix or to estimate the different ingredients to achieve a targeted compressive strength after seven and twenty eight days. To verify the results of the ANNs model, seventeen concrete samples are prepared and tested at laboratory and the same ingredients of the mixes are used to predict the strength and slump using the developed ANN model. The Root Mean Square Error (RMSE) of the results for the slump and the compressive strength after 7 and 28 days equal 3.74, 1.79 and 3.05, respectively. These results showed the ability of the developed ANNs as an effective tool to predict and estimate the compressive strength and slump of concrete in Egypt. The analysis of the test results leads to the conclusion that this idea can be used for the development of valid systems for specifications and standards.
\end{abstract}

\section{INTRODUCTION}

Concrete is one of the most widely used construction material in the world. This is because its flowability in the complicated forms of the structural elements (i.e., highly versatile) and its reasonable strength in hardened state.

Concrete is highly nonlinear composite material and modeling its behavior would be very difficult. The followed empirical equations that is used for estimating compressive strength doesn't take into account the effect of chemical and mineral admixtures. Despite these admixtures became very common in Egypt and has noticeable effect on the concrete properties and there are many companies produce these admixtures with variety of types.

Compressive strength of concrete is unknown during the early life of a structure. Compressive strength is considered to be the most important property of concrete, because it usually indicates its overall quality. Although the strength of concrete can be measured at different ages, codes usually specify standard 28-day for testing at this age concrete take more than 
$80 \%$ from its grade. Earlier testing such as seven days may be useful for the prediction of the 28-day strength of concrete (Neville, 1986) [1].

\section{LITERATURE REVIEW}

Researchers showed that the compressive strength of concrete is determined by the properties of contents of the concrete (Popovic, 1990; Oluokun, 1994) [2, 3]. Strength of concrete may also be estimated by empirical relationships built through multiple linear regressions. However, considering that concrete is a highly nonlinear material, modeling its behavior would be highly difficult. An alternative method to estimate the strength of concrete is by using the ANN approach. ANNs may be trained on available experimental data describing the properties of the material used to produce the concrete. Most researches in this area used the backpropagation networks (Yeh, 1998; Lai and Serra 1997; Nehdi et al., 2001; Dias and Pooliyadda, 2001) $[4,5,6.7]$ to design concrete mixtures and/or to predict its strength. Yeh (1998) [4] showed that ANNs could be used to predict the compressive strength of concrete from the mix proportions of its ingredients based on a large set of experimental data and this would be more accurate than a regression analysis based model (Dias and Pooliyadda 2001) [7].

Most of the mathematical models used to study the behavior of concrete mixes consist of mathematical rules and expressions that capture relationship between components of concrete mixes. Mathematical models generally are in regression forms. However, if the problem contains many independent variables, regression methods cannot be used because of less accuracy and more assumptions in regression forms such as: linear, non-linear, exponential, etc. (Swingler 1996) [8]. In the recent years, new modeling techniques such as artificial neural networks, expert systems can approximate non-linear and complex relation due to any phenomena and trial and error process by learning real record relationship without any presumptions (Dias and Pooliyadda 2001) [7].

Yeh (1999) [9] used the ANNs with nonlinear programming to the optimization of high performance concrete mix proportioning for a given workability and compressive strength. Lai and Serra (1997) [5] developed an ANN model for predicting the compressive strength of concrete with varying aggregate properties based on data from experimental measurements. Kasperkiewicz et al. (1995) [10] demonstrated that an ANN could be used for predicting strength properties of high performance concrete and for searching for optimal concrete mixes. Dias and Pooliyadda (2001) [7] used back propagation networks to predict the strength and slump of ready mixed concrete and high strength concrete with chemical and/or mineral admixtures. They reported that the ANN models performed better than the multiple regression models in reducing the scatter of predictions. Nehdi et al. (2001) [6] demonstrated that ANNs could be used to accurately predict concrete slump, filling capacity and segregation. Also, Kim et al. (2004) [11] and demonstrated that the neural network techniques are effective in estimating the compressive strength of concrete based on the mix proportions.

Researchers tried to predict the compressive strength of concrete using other admixtures or to predict other properties of concrete. Sancak (2009) [12] developed a methodology for prediction of bond strength of lightweight concrete. It was found that there was a high correlation between the experimental bond strengths and the bond strengths predicted by ANN. Demir (2008) [13] applied ANNs to predict elastic modulus of both normal and high strength concrete. Nazari (2013) [14] Applied ANNs to predict the compressive damage of lightweight geopolymer. Barbuta et al. (2012) [15] used ANNs for determining the properties of polymer concrete with fly ash. Atici (2011) [16] used artificial neural network for estimating the compressive strength of concrete that contains various amounts of blast furnace slag and fly ash, based on the properties of the additives. Dantas, et al. (2013) [17] developed an ANN model to predict the compressive strength of concrete made of construction and demolition waste material. Oztas et al. (2005) [18] used the ANNs for developing a methodology for predicting compressive strength of High Strength Concrete (HSC). Bilgil (2012) [19] used ANNs for predicting the slump value of fresh concrete. Pala et al. (2007) [20] studied the effects of fly ash and silica fume replacement content on the strength of concrete cured for a long term period of time by using ANNs. Mazloom (2013) [21] used 
ANNs for predicting the workability of self-compacting concrete. Prasad et al. (2009) [22] used ANN to predict a 28-day compressive strength of a normal and high strength selfcompacting concrete and high performance concrete with high volume fly ash.

\section{Factors affecting slump and compressive strength}

Concrete is a sensitive material where its properties could be affected by many factors. To achieve this study objectives, it is important to identify all factors that have noticeable effect on the concrete compressive strength and slump. By reviewing the literature, these factors are, type and quantity of admixtures, cement type and content, coarse aggregate type and content, coarse aggregate size, fine aggregate content, fineness modulus of fine aggregate and watercement ratio.

This study aims to predicting three important properties of fresh state (slump) and hardened state (compressive strength at 7 and 28 days age) for concrete produced in Egypt with local materials using ANNs. Also, a computer program is developed to facilitate the use of the proposed ANN model in mix design. Compressive strength after seven days $\left(\mathbf{C}_{7}\right)$ is a very important parameter to find the quality of concrete in its early age to help in approving the construction work to some extent. Compressive strength after 28 Days $\left(\boldsymbol{C}_{28}\right)$ is an important property where codes usually specify standard 28 days for measuring the compressive strength. At this age concrete reaches more than $80 \%$ from its grade. Initial Slump is used to measure the workability of fresh concrete.

\section{Data collection}

The final list of the factors affecting concrete slump and compressive strength which will be considered as the inputs of the ANN model along with the output factors are listed in Table 1. Data pertain the identified factors that affect both the slump and compressive strength are collected from different batch plants distributed all over the Arab Republic of Egypt. For that purpose, 1000 concrete samples are collected which represent different concrete components with different admixture contents to cover all possibilities in concrete mixes. All concrete samples were cured under normal conditions. Based on the data collected for all the factors, the range of these factors are presented in Table 2. The actual compressive strength after seven days, twenty eight days and the initial slump of the samples are, also, collected. These data represent laboratory results from different construction projects. Some of the concrete samples were deleted from the data due to special curing conditions, etc.

Table 1: NN model input and output variables

\begin{tabular}{|c|c|c|c|c|}
\hline \multirow{6}{*}{ 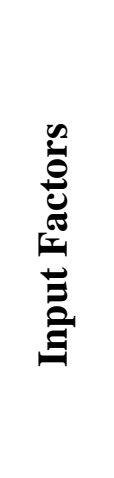 } & No & Variable & No & Variable \\
\hline & 1 & Cement type & 6 & $\begin{array}{l}\text { Fine aggregate content (Sand, } \\
\mathrm{kg} / \mathrm{m}^{3} \text { ) }\end{array}$ \\
\hline & 2 & Cement content $\left(\mathrm{kg} / \mathrm{m}^{3}\right)$ & 7 & $\begin{array}{l}\text { Fineness modulus of fine } \\
\text { aggregate }\end{array}$ \\
\hline & 3 & Coarse aggregate type & 8 & Admixture type \\
\hline & 4 & $\begin{array}{l}\text { Coarse aggregate content } \\
\left(\mathrm{kg} / \mathrm{m}^{3}\right)\end{array}$ & 9 & Admixture dosage \\
\hline & 5 & Coarse aggregate size $\left(\mathrm{MNS}^{*}\right)$ & 10 & Water cement ratio \\
\hline \multirow{3}{*}{ 象 } & 1 & \multicolumn{3}{|l|}{ Initial slump (mm) } \\
\hline & 2 & \multicolumn{3}{|c|}{ Compressive strength after seven days $\left(\mathrm{C}_{7}, \mathrm{Mpa}\right)$} \\
\hline & 3 & \multicolumn{3}{|c|}{ Compressive strength after twenty eight days $\left(\mathrm{C}_{28}, \mathrm{Mpa}\right)$} \\
\hline
\end{tabular}

*MNS: Maximum nominal size

\section{DATA NORMALIZATION}

To improve the generalization ability of the ANNs and for better comparison and avoiding the influence of greater values parameters, input and output data are normalized for effective 
training of the model being developed. The normalization of the data is the scaling of all input and output pairs within the range $(0,1)$ using Eq. 1. It is used to allow the squashing of the values to improve the network performance (Hegazy et al. 1994) [23]. Furthermore, the neural networks usually provide improved performance when the data lie within the range $(0,1)$ (Seleemah 2005) [24].

Table 2: Collected data range

\begin{tabular}{|c|c|c|c|c|}
\hline No & \multicolumn{2}{|r|}{ Variable description } & Min. & Max. \\
\hline \multirow[b]{2}{*}{$1-$} & \multirow[b]{2}{*}{ Cement } & Ordinary Portland cement content $\left(\mathrm{kg} / \mathrm{m}^{3}\right)$ & 275 & 550 \\
\hline & & $\begin{array}{l}\text { Sulphate resistant Portland cement content } \\
\left(\mathrm{kg} / \mathrm{m}^{3}\right)\end{array}$ & 270 & 525 \\
\hline \multirow{3}{*}{$2-$} & \multirow{3}{*}{ Admixtures } & Type $\mathrm{G}$ (\% by weight of cement) & 1.22 & 2.5 \\
\hline & & Type F (\% by weight of cement) & 0.90 & 3.09 \\
\hline & & Type D (\% by weight of cement) & 0.75 & 1.3 \\
\hline \multirow{4}{*}{$3-$} & \multirow{4}{*}{$\begin{array}{l}\text { Coarse } \\
\text { aggregate }\end{array}$} & Crushed Dolomite I MNS* $(10 \mathrm{~mm})$ & 320 & 1180 \\
\hline & & Crushed Dolomite II MNS* $(20 \mathrm{~mm})$ & 350 & 800 \\
\hline & & Gravel $\left(\mathrm{kg} / \mathrm{m}^{3}\right)$ & 1070 & 1240 \\
\hline & & MNS* for gravel $(\mathrm{mm})$ & 20 & 37.5 \\
\hline \multirow{2}{*}{ 4- } & \multirow{2}{*}{$\begin{array}{c}\text { Fine } \\
\text { aggregate }\end{array}$} & Sand $\left(\mathrm{kg} / \mathrm{m}^{3}\right)$ & 460 & 980 \\
\hline & & Fineness modulus for sand & 1.56 & 3.1 \\
\hline \multirow{3}{*}{$5-$} & \multirow{3}{*}{$\begin{array}{l}\text { Absorption } \\
\text { ratio }\end{array}$} & Gravel & 0.54 & 0.91 \\
\hline & & Crushed dolomite I \& II & 0.6 & 1.0 \\
\hline & & Fine aggregate (Sand) & 1.12 & 1.94 \\
\hline 6- & \multicolumn{2}{|c|}{ Water cement ratio } & 0.32 & 0.59 \\
\hline 7- & \multicolumn{2}{|c|}{ Initial slump (mm) } & 125 & 250 \\
\hline $8-$ & \multicolumn{2}{|c|}{ Actual compressive strength after seven days $\left(\mathrm{C}_{7}, \mathrm{Mpa}\right)$} & 15.4 & 37.6 \\
\hline 9- & \multicolumn{2}{|c|}{ Actual compressive strength after twenty eight days $\left(\mathrm{C}_{28}, \mathrm{Mpa}\right)$} & 20.2 & 72.1 \\
\hline
\end{tabular}

*MNS: Maximum nominal size

Scaled value for any item $=\left[\frac{(\text { Originnal value }- \text { Min value })}{(\text { Max value }- \text { Min value })}\right]$

Where, Max value and Min value are the maximum and minimum data values within a specific data set. The output of the network is obtained in the form of normalized output (scaled value) which is then de-normalized to actual values as used for preparing the training set according to Eq.2.

Original value $=[$ Scaled value $($ Max value - Min value $)]+$ Min value

\section{Neural network model for estimating concrete slump and compressive strength}

Having identified the main factors that affect the fresh concrete (slump) and the hardened concrete (compressive strength) and collecting their relevant data, an ANN model is developed that uses these factors as the inputs and the slump and compressive strength at seven and 28 days as the outputs. The major strength of ANN is their ability to learn from examples and to generalize that knowledge to novel cases. Using an appropriately configured ANN model and a sufficient set of previously completed concrete samples, an ANN model would be able to arrive at almost accurate forecasts of the slump and compressive strength of 
concrete samples. Based on this concept, the development of the ANNs model proceeded in three phases: design phase, implementation phase and validation phase. The design phase addresses the preliminary planning of the ANNs model and its variable representation. The implementation phase entails setting the configuration, changing the model parameters for improved performance and increased accuracy in prediction and training of the ANNs model and testing for proper functioning. Finally, the validation phase addresses the final validation of the developed model.

\subsection{Design phase}

In this study, the ANN were designed to have an input layer that consists of ten input nodes representing the factors that affect concrete slump and compressive strength as listed in Table 1. Two widely used types of Portland cement of grade 42.5 where used in all mixtures (Sulphate resistant Portland cement and Ordinary Portland cement). For the coarse aggregate, three types are used: gravel, crushed dolomite (aggregate I and aggregate II) and crushed basalt (aggregate I and aggregate II). Water reducing and retarder (type D), high range water reducing superplasticizer (types F) and high range water reducing and retarder (G) are used in this study. These types are used as they represent the most common superlasticizers used in concrete mixes in Egypt.

The first step of designing the ANN model is to identify the data representation scheme for each input and output variable. As shown in Table 2, this is entirely dependent on the nature of each factor. Some factors, such as cement content, coarse aggregate content, gravel MNS, sand content, fineness modulus, admixture dosage and water cement ratio have numerical nature and thus represented by their corresponding numerical values. Other factors have linguistic or non-numerical nature, such as cement type, coarse aggregate type and admixture type. These factors are represented through equivalent numerical values. For example, the cement type has been represented using numerical values as: two to represent sulphate resistant Portland cement and one to represent ordinary Portland cement. The output layer consists of three nodes representing the compressive strength after 7 and 28 days of the hardened concrete and the slump of the fresh concrete.

Configuring the ANN is a complex and dynamic process that requires the determination of the internal structure and rules (i.e., network architecture, learning algorithm, the number of hidden layers and neurons in each layer...etc). Although it takes longer time to train a network, using higher number of training patterns increases the ability of the network to learn and achieve more accurate results (Hegazy et al. 1994) [23]. Figure (1) shows a typical architecture of multilayer feed-forward neural network with an input layer, an output layer and one hidden layer.

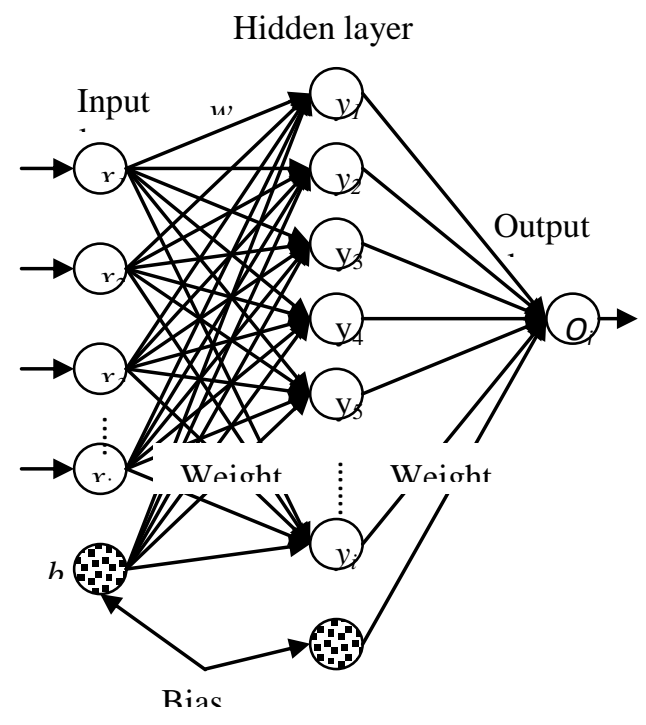

Fig. 1: Typical structure of a multi-layer ANN 
As shown in Figure (1), the artificial neurons are arranged in layers, and all the neurons in each layer have connections to all the neurons in the next layer. Associated with each connection between these artificial neurons a weight value $\left(w_{i}\right)$ so that the total inputs $\left(x_{i}\right)$ to the single neuron is:

input $=\sum_{i=1}^{n} w_{i} x_{i}+b$

Where: $\mathrm{b}$ is the connection weight associated with a bias node having input value $=1$.

This input passes through an activation function to produce the values of $y_{i}$ of the hidden layer(s) or $O_{i}$ of the output layer. The activation function may have many forms. The most familiar and effective form is the sigmoid function, (Seleemah 2005) [24] as:

$$
\text { Ouput }=\frac{1}{1+\exp ^{-\alpha(i p u t)}}
$$

Where: $\alpha$ is a constant that typically varies between 0.01 and 1.00 .

Signals are received at the input layer, pass through the hidden layers and reach the output layer producing the output of the network. The learning process primarily involves the determination of connection weights and bias matrices and the pattern of connections. It is through the presentation of examples, or training cases, and application of the learning rule that the neural network obtains the relationship embedded in the data.

One important issue of multilayer feed-forward ANNs is to determine the appropriate number of hidden layers and the number of neurons in each layer. This process is done through trial and error. There is no unique solution for representation schemes. Different ANNs can produce similar results with the same set of training data (Seleemah 2005). Hegazy et al. (1994) [23, 24] suggested that the number of hidden nodes may be estimated as one-half of the total input and output nodes. Sodikov and Student (2005) [25], on the other hand, suggested that the minimum number of hidden nodes can be more than or equal to $(p-1) /(n$ +2 ), where $p$ is the number of the training examples, and $n$ is the number of inputs. In this study, an iterative process is used of increasing the number of nodes in one and two hidden layers till the network reaches its desired performance.

Also, it is important to determine which training procedure to adopt. There are many alternative paradigms to choose from. The back propagation algorithm which belongs to the realm of supervised learning rule is the most widely used training technique for problems similar to the current study (Seleemah 2005) [24]. Accordingly, the back-propagation learning algorithm (supervised training) is used to perform the training requirements and to construct the current model.

\subsection{Training and implementation phase}

It is important to choose which training procedure to adopt in order to achieve the optimum performance. There are many alternative paradigms to choose from. In this study multilayer feedforward and back propagation algorithm are used, and the optimum performance in this study was achieved by trial and error according to the following literature guide. While an initial ANN model for estimating concrete properties has been developed, this model needs refinement to reach the optimum performance. For a systematic implementation of this phase, a parametric analysis of several ANN parameters is conducted. This include parameters such as training function, learning function, number of hidden layers, and number of nodes in hidden layer. The optimum performance presumably provides minimum error for the resulting output. This is calculated through the root mean square error (RMSE). Despite there are no generalized rules to determine the size of the training data, in this study, it was decided to use $70 \%$ of the data cases for training, $15 \%$ of the data for testing, and $15 \%$ for validation. These sets were randomly selected and extracted from the data. Different transfer functions (Tansig, Logsig, Purelin), different learning function (TRAINBFG, TRAINCGB, TRAINLM, TRAINCGF, TRAINCGP, TRAINGDM, TRAINGDA, ....etc.) and different network have been experimented with. All different cases that experimented with are presented in Table 3 .

As per the different experiments conducted, the best network used the Sigmoid activation function (AF) for all hidden layers. The network consists of four hidden layers with 10 neurons in each layer with learning rate (LR) of 0.55 , momentum factor (MF) of 0.55 and 8000 training cycles (Network $\mathrm{N}_{33}$ as presented in Table 3). 

IN EGYPT

Table 3: Comparison between different NN architectures

\begin{tabular}{|c|c|c|c|c|c|c|c|c|}
\hline & ork & Architecture & $\begin{array}{l}\text { AF For } \\
\text { Hidden }\end{array}$ & $\begin{array}{l}\text { AF For } \\
\text { Output }\end{array}$ & $\mathbf{L R}$ & MF & $\begin{array}{l}\text { No. of } \\
\text { Iteration }\end{array}$ & MSE \\
\hline & $\mathrm{N}_{1}$ & $10-10-3$ & purelin & purelin & 0.02 & 0.5 & 10000 & 0.0044 \\
\hline & $\mathbf{N}_{2}$ & $10-15-3$ & $\operatorname{logsig}(\mathbf{x})$ & $\operatorname{logsig}(x)$ & 0.04 & 0.55 & 20000 & 0.0227 \\
\hline$\frac{y}{0}$ & $\mathbf{N}_{3}$ & $10-20-3$ & $\operatorname{tansig}(x)$ & $\operatorname{tansig}(x)$ & 0.06 & 0.6 & 30000 & 0.0061 \\
\hline 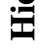 & $\mathbf{N}_{4}$ & $10-25-3$ & purelin & purelin & 0.08 & 0.65 & 40000 & 0.0044 \\
\hline$\stackrel{\mathscr{E}}{\Xi}$ & $\mathbf{N}_{5}$ & $10-30-3$ & $\operatorname{logsig}(x)$ & $\operatorname{logsig}(x)$ & 0.2 & 0.7 & 100000 & 0.0242 \\
\hline 0 & $\mathbf{N}_{6}$ & $10-35-3$ & $\operatorname{tansig}(x)$ & $\operatorname{tansig}(x)$ & 0.4 & 0.75 & 200000 & 0.059 \\
\hline & $\mathbf{N}_{7}$ & $10-40-3$ & purelin & purelin & 0.6 & 0.5 & 500000 & 0.0043 \\
\hline & $\mathbf{N}_{8}$ & $10-50-3$ & $\operatorname{logsig}(x)$ & $\operatorname{logsig}(x)$ & 0.8 & 0.55 & 10000 & 0.0224 \\
\hline & $\mathrm{N}_{9}$ & $10-10-10-3$ & $\tan \operatorname{sig}(x)$ & tansig(x) & 0.9 & 0.6 & 20000 & 0.0060 \\
\hline Dे & $\mathbf{N}_{10}$ & $10-15-15-3$ & purelin & purelin & 0.02 & 0.65 & 30000 & 0.0045 \\
\hline$\stackrel{\mathscr{J}}{=}$ & $\mathbf{N}_{11}$ & $10-20-20-3$ & $\operatorname{logsig}(\mathbf{x})$ & $\operatorname{logsig}(x)$ & 0.04 & 0.7 & 40000 & 0.0223 \\
\hline 훙 & $\mathbf{N}_{12}$ & $10-25-25-3$ & $\operatorname{tansig}(x)$ & $\operatorname{tansig}(x)$ & 0.06 & 0.75 & 100000 & 0.0075 \\
\hline ?ำ & $\mathbf{N}_{13}$ & $10-30-30-3$ & purelin & purelin & 0.08 & 0.5 & 200000 & 0.0046 \\
\hline 0 & $\mathbf{N}_{14}$ & $10-35-35-3$ & $\operatorname{logsig}(\mathbf{x})$ & $\operatorname{logsig}(x)$ & 0.2 & 0.55 & 500000 & 0.023 \\
\hline 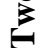 & $\mathbf{N}_{15}$ & $10-40-40-3$ & $\operatorname{tansig}(x)$ & tansig(x) & 0.4 & 0.6 & 10000 & 0.0502 \\
\hline & $\mathbf{N}_{16}$ & $10-50-50-3$ & purelin & purelin & 0.6 & 0.65 & 20000 & 0.0036 \\
\hline & $\mathbf{N}_{17}$ & $10-10-10-10-3$ & $\operatorname{logsig}(\mathbf{x})$ & $\operatorname{logsig}(\mathbf{x})$ & 0.8 & 0.7 & 30000 & 0.0229 \\
\hline है & $\mathbf{N}_{18}$ & $10-15-15-15-3$ & $\operatorname{tansig}(x)$ & $\operatorname{tansig}(x)$ & 0.9 & 0.75 & 40000 & 0.0058 \\
\hline ב & $\mathbf{N}_{19}$ & $10-20-20-20-3$ & purelin & purelin & 0.02 & 0.5 & 100000 & 0.0046 \\
\hline$\frac{\overline{0}}{0}$ & $\mathbf{N}_{20}$ & $10-25-25-25-3$ & $\operatorname{logsig}(\mathbf{x})$ & $\operatorname{logsig}(x)$ & 0.04 & 0.55 & 200000 & 0.0229 \\
\hline 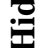 & $\mathbf{N}_{21}$ & $10-30-30-30-3$ & $\tan \operatorname{sig}(x)$ & $\tan \operatorname{sig}(x)$ & 0.06 & 0.6 & 500000 & 0.0072 \\
\hline 8 & $\mathbf{N}_{22}$ & 10-35-35-35-3 & purelin & purelin & 0.08 & 0.65 & 10000 & 0.0045 \\
\hline 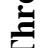 & $\mathbf{N}_{23}$ & $10-40-40-40-3$ & $\operatorname{logsig}(\mathbf{x})$ & $\operatorname{logsig}(\mathbf{x})$ & 0.2 & 0.7 & 20000 & 0.0223 \\
\hline & $\mathbf{N}_{24}$ & $10-50-50-50-3$ & $\tan \operatorname{sig}(x)$ & $\operatorname{tansig}(x)$ & 0.4 & 0.75 & 30000 & 0.0054 \\
\hline & $\mathbf{N}_{25}$ & 10-10-10-10-10-3 & purelin & purelin & 0.6 & 0.5 & 40000 & 0.004 \\
\hline$\stackrel{d}{2}$ & $\mathbf{N}_{26}$ & $10-15-15-15-15-3$ & $\operatorname{logsig}(\mathbf{x})$ & $\operatorname{logsig}(\mathbf{x})$ & 0.8 & 0.55 & 100000 & 0.0235 \\
\hline$\stackrel{\sigma}{\Xi}$ & $\mathbf{N}_{27}$ & $10-20-20-20-20-3$ & $\tan \operatorname{sig}(x)$ & $\tan \operatorname{sig}(x)$ & 0.9 & 0.6 & 200000 & 0.0071 \\
\hline$\frac{\pi}{0}$ & $\mathbf{N}_{28}$ & $10-25-25-25-25-3$ & purelin & purelin & 0.02 & 0.65 & 500000 & 0.0045 \\
\hline 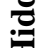 & $\mathbf{N}_{29}$ & $10-30-30-30-30-3$ & $\operatorname{logsig}(x)$ & $\operatorname{logsig}(\mathbf{x})$ & 0.04 & 0.7 & 10000 & 0.0238 \\
\hline$=$ & $\mathbf{N}_{30}$ & 10-35-35-35-35-3 & $\operatorname{tansig}(x)$ & $\operatorname{tansig}(\mathbf{x})$ & 0.06 & 0.75 & 20000 & 0.0075 \\
\hline$\overline{0}$ & $\mathbf{N}_{31}$ & $10-40-40-40-40-3$ & purelin & purelin & 0.08 & 0.5 & 30000 & 0.0043 \\
\hline & $\mathbf{N}_{32}$ & $10-50-50-50-50-3$ & $\operatorname{logsig}(\mathbf{x})$ & $\operatorname{logsig}(\mathbf{x})$ & 0.02 & 0.5 & 40000 & 0.0226 \\
\hline & $\mathbf{N}_{33}$ & $10-10-10-10-10-10-3$ & $\tan \operatorname{sig}(\mathbf{x})$ & $\operatorname{tansig}(\mathbf{x})$ & 0.4 & 0.55 & 8000 & 0.0033 \\
\hline$\sum^{0}$ & $\mathbf{N}_{34}$ & $10-15-15-15-15-15-3$ & purelin & purelin & 0.6 & 0.6 & 200000 & 0.0043 \\
\hline$\stackrel{\text { g }}{=}$ & $\mathbf{N}_{35}$ & $10-20-20-20-20-20-3$ & $\operatorname{logsig}(\mathbf{x})$ & $\operatorname{logsig}(\mathbf{x})$ & 0.8 & 0.65 & 50000 & 0.0234 \\
\hline है & $\mathbf{N}_{36}$ & $10-25-25-25-25-25-3$ & $\tan \operatorname{sig}(x)$ & $\tan \operatorname{sig}(x)$ & 0.9 & 0.7 & 10000 & 0.0055 \\
\hline 胥 & $\mathbf{N}_{37}$ & $10-30-30-30-30-30-3$ & purelin & purelin & 0.02 & 0.75 & 20000 & 0.0043 \\
\hline ti & $\mathbf{N}_{38}$ & 10-35-35-35-35-35-3 & $\operatorname{logsig}(\mathbf{x})$ & $\operatorname{logsig}(\mathbf{x})$ & 0.04 & 0.5 & 30000 & 0.0238 \\
\hline$\sum$ & $\mathbf{N}_{39}$ & $10-40-40-40-40-40-3$ & $\tan \operatorname{sig}(\mathbf{x})$ & $\operatorname{tansig}(x)$ & 0.06 & 0.55 & 40000 & 0.0083 \\
\hline & $\mathbf{N}_{40}$ & $10-50-50-50-50-50-3$ & purelin & purelin & 0.08 & 0.6 & 100000 & 0.0043 \\
\hline & $\mathbf{N}_{41}$ & $10-10-10-10-10-10-10-3$ & $\operatorname{logsig}(\mathbf{x})$ & $\operatorname{logsig}(\mathbf{x})$ & 0.5 & 0.4 & 100000 & 0.0041 \\
\hline క్రి & $\mathbf{N}_{42}$ & $10-15-15-15-15-15-15-3$ & $\operatorname{tansig}(\mathbf{x})$ & $\operatorname{tansig}(\mathbf{x})$ & 0.4 & 0.7 & 500000 & 0.0050 \\
\hline$\underline{a}$ & $\mathbf{N}_{43}$ & $10-20-20-20-20-20-20-3$ & $\tan \operatorname{sig}(\mathbf{x})$ & $\tan \operatorname{sig}(x)$ & 0.9 & 0.6 & 200000 & 0.0060 \\
\hline$\frac{0}{\sigma}$ & $\mathbf{N}_{44}$ & 10-25-25-25-25-25-25-3 & purelin & purelin & 0.02 & 0.65 & 500000 & 0.0044 \\
\hline 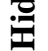 & $\mathbf{N}_{45}$ & $10-30-30-30-30-30-30-3$ & $\operatorname{logsig}(\mathbf{x})$ & $\operatorname{logsig}(\mathbf{x})$ & 0.04 & 0.7 & 10000 & 0.0229 \\
\hline 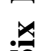 & $\mathbf{N}_{46}$ & $10-35-35-35-35-35-35-3$ & $\operatorname{tansig}(\mathbf{x})$ & $\operatorname{tansig}(\mathbf{x})$ & 0.06 & 0.75 & 20000 & 0.0094 \\
\hline מ & $\mathbf{N}_{47}$ & $10-40-40-40-40-40-40-3$ & purelin & purelin & 0.06 & 0.75 & 20000 & 0.0047 \\
\hline
\end{tabular}

L.R=Learning Rate, M=Momentum, A.F=Activation Function, M.S.E=Mean Square Error 
After the training and testing of the developed ANN model, the best performance network with the minimum MSE (as shown in Table 3 ) is used to forecast the $\mathrm{C}_{7}, \mathrm{C}_{28}$ and slump.

To facilitate the implementation process and the use of the developed ANN model, a computer program is developed with a user-friendly interface using MATLAB ${ }^{\circledR}$ (Fig. 2). The user can easily use this interface to predict the concrete slump and compressive strength for any concrete mix. This user interface is the way that the program accepts instruction from user and presents results. The user simply enters the data pertaining to any concrete mix and the outputs are directly presented as shown in Fig. 2. To facilitate the data entry, a drop down menu is presented to the user to select the appropriate value for a given variable. After the mix constituents are entered, the user presses the calculate button (Fig. 2) to obtain the $C_{7}, C_{28}$ and slump.

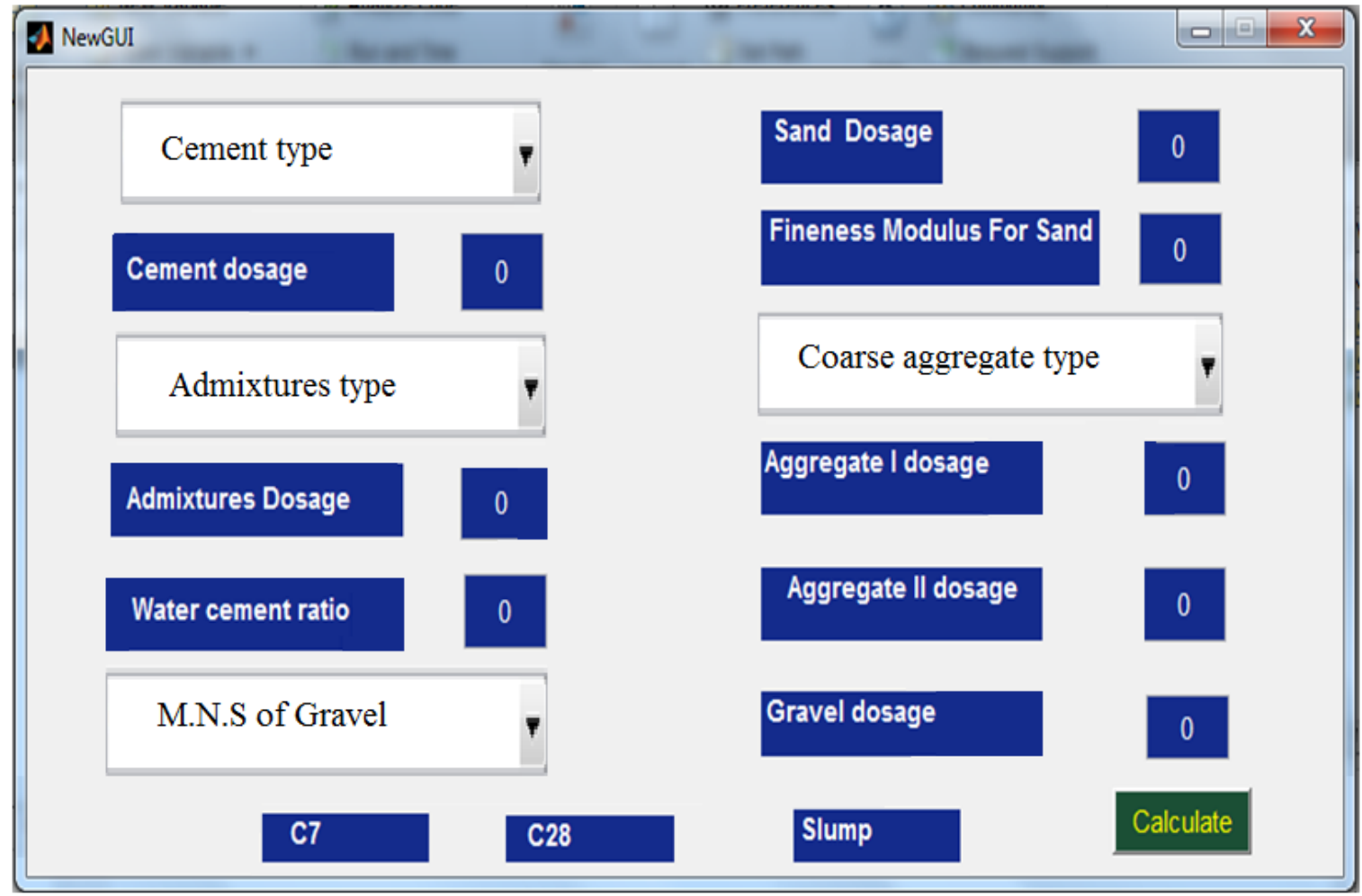

Fig. 2: The user interface of the developed program

The developed computer program can be used either to predict the slump/compressive strength for a given concrete mix or to find the mix components to achieve a given slump/compressive strength. In the second case, for example, the user may want to design a concrete mix to achieve a compressive strength of $30 \mathrm{MPa}$ after 28 days. In this case, by trial and error, the user may try different values for the mix components until the desired compressive strength is achieved.

\section{ANN MODEL VALIDATION}

In order to validate the developed model against a new set of samples, seventeen concrete specimens with known parameters are prepared in the laboratory in the form of $150 \times 150 \times 150$ mm cubes.

\subsection{Materials}

The properties of the produced samples as the following: Commercially available two types of cement of grade 42.5 and specific gravity of 3.15 are used, namely, sulphate resistant Portland cement and ordinary Portland cement. Two types of course aggregate are used, namely, gravel and dolomite I \& II. Aggregate MNS is $20 \mathrm{~mm}$ for gravel, $10 \mathrm{~mm}$ for 
aggregate I and $20 \mathrm{~mm}$ for aggregate II. The fine aggregate used is sand with fineness modulus of 2.4 and 2.7. Three types of admixtures are used including Sikament®-R2004 (type G), Sikament ${ }^{\circledR}-\mathrm{N}$ (type F) and Master Rheobuild 840 (type D).

\subsection{Design of concrete mixes}

All concrete mixes are designed using the absolute volume method. In this method, the proportions are given per cubic meter, then the proportions that give the required quantities for the seventeen concrete specimens (three cubes for each age) where calculated.

\subsection{Casting, curing and testing of specimen}

Seventeen concrete cube specimens $150 * 150 * 150 \mathrm{~mm}$ where casted in the laboratory. Before casting the initial slump of the concrete was measured accordance the Egyptian code. All specimens where immersed in water for 24 hours after their initial setting time. Then, these specimens where cured for periods of 7 and 28 days. At the end of the curing period, the specimens were removed from water and air dried before testing in compression. Three cubes for each age were crushed using the compression testing machine and the average of the three results was taken as the compressive strength of the concrete.

\section{RESULTS AND DISCUSSIONS}

Figures 3, 4 and 5 show a comparison between the laboratory test results and the developed ANN model results for the slump, compressive strength after 7days and compressive strength after 28 days, respectively

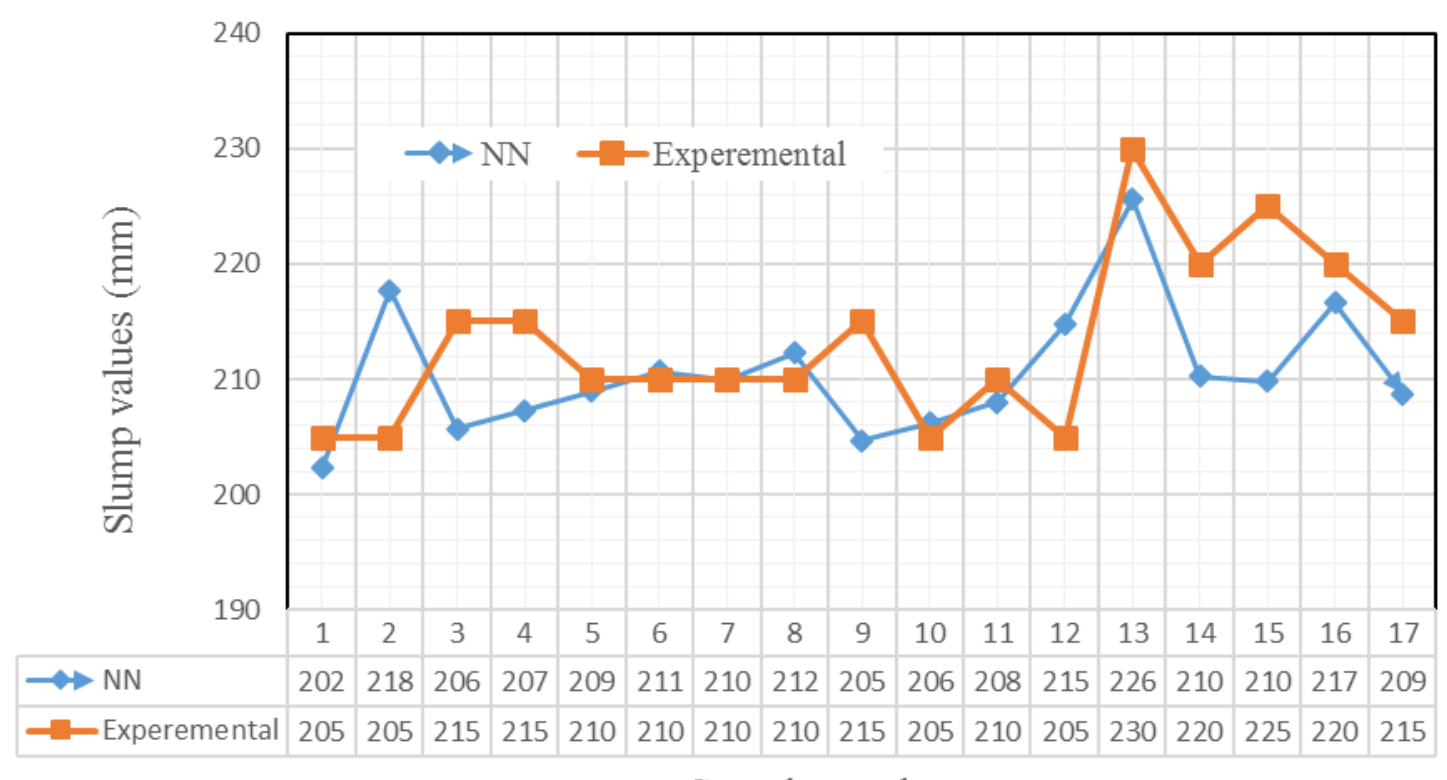

Sample number

Fig. 3: Comparison between ANN model and the experimental results for slump 


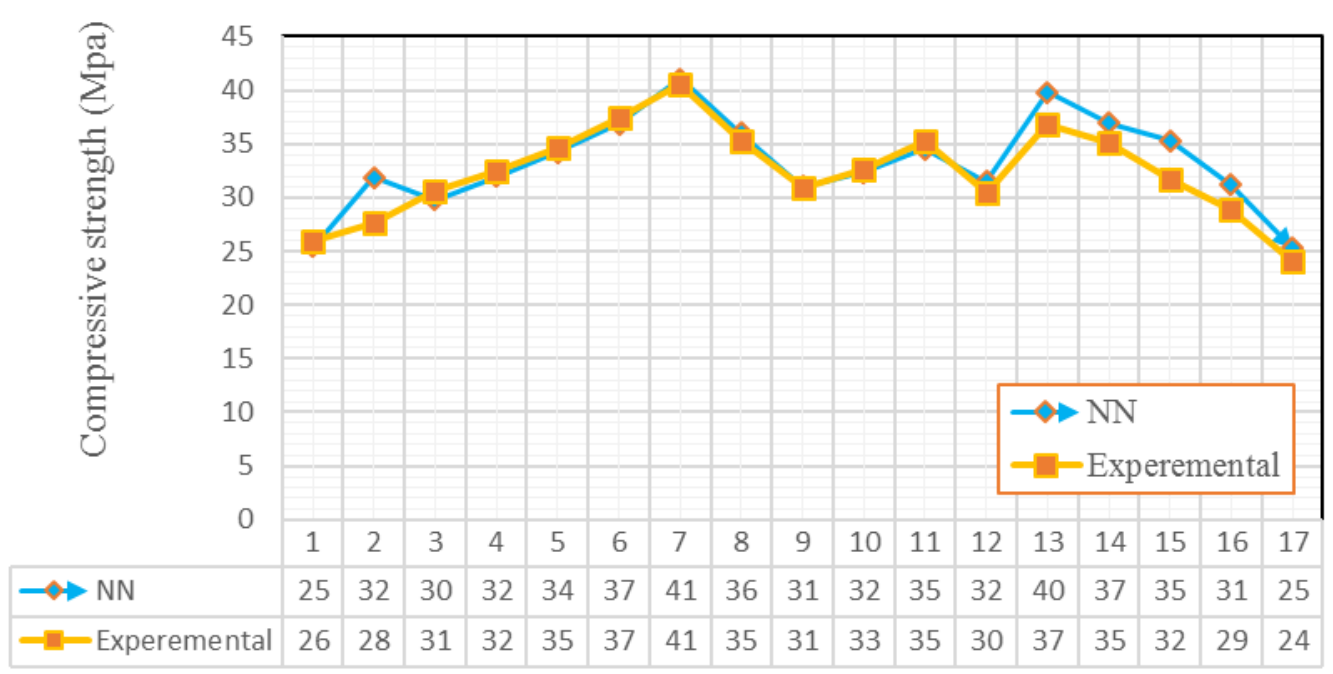

Sample number

Fig. 4: Comparison between ANN model and the experimental results for compressive strength after 7 days

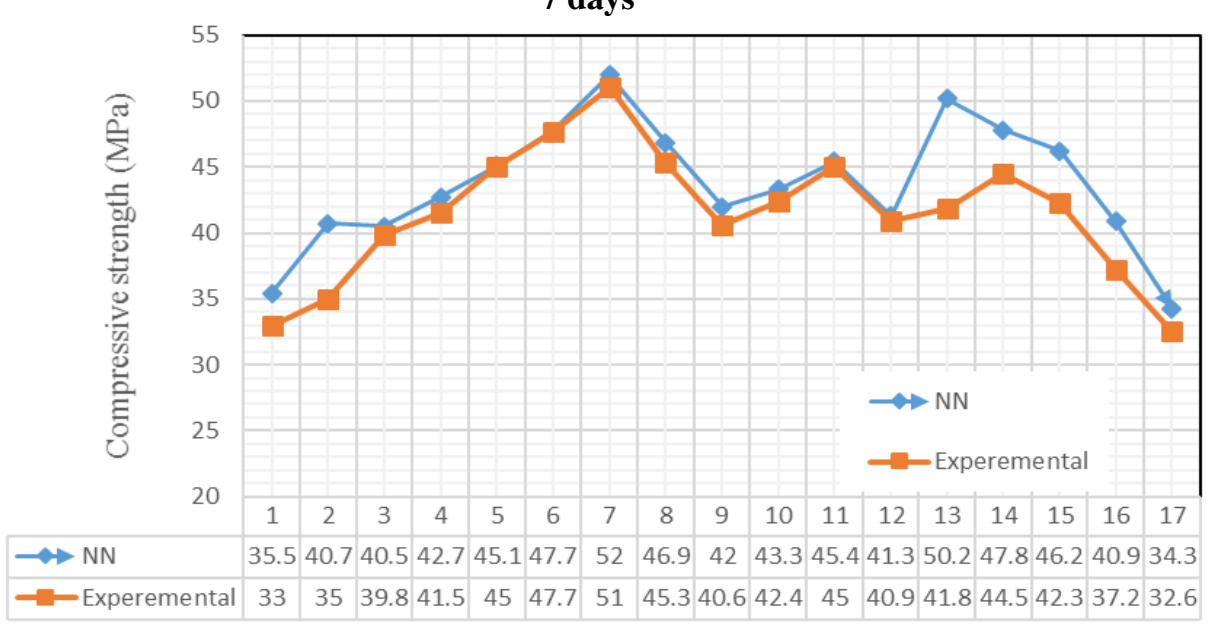

Sample number

Fig. 5: Comparison between ANN model and the experimental results for compressive strength after 28 days

To measure the performance of the developed ANN model, different performance measurements used including the RMSE, the mean absolute percentage error (MAPE) and the correlation coefficient (R) as presented in Eqs. 5, 6 and 7, respectively.

$$
\begin{array}{r}
\text { RMSE }=\sqrt{\frac{1}{n} \sum_{i=1}^{n}\left(o_{i}-t_{i}\right)^{2}} \\
\text { MAPE }=\frac{1}{n} \sum_{i=1}^{n} \frac{\left\|o_{i}-t_{i}\right\|}{t_{i}} * 100
\end{array}
$$




$$
\mathrm{R}=\frac{\sum_{i=1}^{n}\left(O_{i}-\bar{O}_{i}\right)\left(t_{i}-\bar{t}_{i}\right)}{\sqrt{\sum_{i=1}^{n}\left(O_{i}-\bar{O}_{i}\right)^{2} \sum_{i=1}^{n}\left(t_{\bar{i}}-\bar{t}_{i}\right)^{2}}}
$$

Where $t_{i}$ the obtained value from the experiments, $O_{i}$ is the predicted value from the developed ANN model and $n$ is the total number of samples. The MAPE of the slump, $\mathrm{C}_{7}$ and $\mathrm{C}_{28}$ equal 1.18, 2.93 and 5.47, respectively. The RMSE of the slump, $\mathrm{C}_{7}$ and $\mathrm{C}_{28}$ are 3.74, 1.79 and 3.05 respectively. The $\mathrm{R}$ coefficient of the results for the slump, $\mathrm{C}_{7}$ and $\mathrm{C}_{28}$ equal $0.742,0.93$ and 0.895 , respectively. The results prove the ability of the developed $\mathrm{NN}$ model to predict the slump of the fresh concrete and the compressive strength of the hardened concrete to a high level of accuracy.

\section{SUMMARY AND CONCLUSION}

Recent information technology developments had high impact on concrete technology. ANNs have strong potential as a feasible tool for predicting compressive strength and slump value with acceptable error. The proposed algorithm is expected to have lower cement and water content, higher durability, reduce the number of trial and error, reduce cost, time and give better results when compared to the conventional methods. This idea can be used also for development of valid systems for specifications and standards. The Correlation coefficient of the test results for the slump, $\mathrm{C}_{7}$ and $\mathrm{C}_{28}$ were $0.742,0.93$ and 0.895 , respectively. The RMSE values of the test results for the slump, $\mathrm{C}_{7}$ and $\mathrm{C}_{28}$ were $3.74,1.79$ and 3.05 respectively. The test results of the developed model showed its ability to for predicting concrete properties. Also, the developed model could be used for the design of the concrete mix to achieve a given compressive strength.

\section{REFERENCES}

[1] Neville, A. M, "Properties of Concrete". Longman Scientific and Technical, Third Edition, New York, (1986).

[2] Popovic, S, "Analysis of Concrete Strength versus Water-Cement Ratio Relationship," ACI Materials Journal, Vol. 87, No. 5, pp. 517-529, (1990).

[3] Oluokun, F.A, "Fly Ash Concrete Mix Design and the Water-Cement Ratio Law," ACI Materials Journal, Vol. 91, No. 4, pp. 362-371, (1994).

[4] Yeh, I.C, "Modelling of Strength of High-Performance Concrete Using ANN," Cement and Concrete Research, Vol. 28, No. 12, pp. 1797-1808, (1998).

[5] Lai, S. and Serra, M, "Concrete Strength Prediction by Means of Neural Network," Construction and Building Materials, Vol. 11, No. 2, pp. 93-98, (1997).

[6] Nehdi, M., Djebbar, Y. and Khand, A, "Neural Network Model for Preformed Foam Cellular Concrete," ACI Materials Journal, Vol. 98, No. 5, pp. 402-410, (2001).

[7] Dias, W.P.S. and Pooliyadda, S.P, "Neural Networks for Predicting Properties of Concretes with Admixtures," Construction and Building Materials, Vol. 15, pp. 371379, (2001).

[8] Swingler, K, Applying Neural Networks: A Practical Guide. Third edition, International bock number 0-12-679170-8, Academic Press, New York, (1996).

[9] Yeh, I.C, "Design of High-Performance Concrete Mixture Using Neural Networks and Nonlinear Programming," Journal of Computing in Civil Engineering Vol. 13, No. 1, pp. 36-42, (1999).

[10] Kasperkiewicz, J., Raez, J. and Dubrawski, A, "High-Performance Concrete Strength Prediction Using Artificial Neural Network," Journal of Computing in Civil Engineering, Vol. 9, No. 4, pp. 279-284, (1995).

[11] Kim, J., Kim, D., Feng, M. and Yazdani, F, "Application of Neural Networks for Estimation of Concrete Strength," Journal of Materials in Civil Engineering, Vol. 16, No. 3, pp. 257-264, (2004).

[12] Sancak, E, "Prediction of Bond Strength of Lightweight Concretes by Using Artificial Neural Networks," Scientific Research and Essay, Vol. 4, No. 4, pp. 256-266, (2009). 
[13] Demir, F, "Prediction of Elastic Modulus of Normal and High Strength Concrete by Artificial Neural Networks," Construction and Building Materials, Vol. 22, pp. 14281435, (2008).

[14] Nazari, A, "Artificial Neural Networks Application to Predict the Compressive Damage of Lightweight Geopolymer," Neural Computation and Applications, Vol. 23, pp. 507518, (2013).

[15] Barbuta, M., Diaconescu, R. and Harja, M, "Using Neural Networks for Prediction of Properties of Polymer Concrete with Fly Ash," Journal of Materials in Civil Engineering, Vol. 24, No. 5, pp. 523-528, (2012).

[16] Atici, U, "Prediction of the Strength of Mineral Admixture Concrete Using Multi Variable Regression Analysis and an Artificial Neural Network," Expert Systems with Applications, Vol. 38, pp. 9609-9618, (2011).

[17] Dantas, A., Leite, M. and Nagahama, k, "Prediction of Compressive Strength of Concrete Containing Construction and Demolition Waste Using Artificial Neural Network," Construction and Building Materials, Vol. 38, pp. 717-722, (2013).

[18] Oztas, A., Ozbay, O., Pala, M. and Yuce, M, "Appraisal of Long-Term Effects of Fly Ash and Silica Fume on Compressive Strength of Concrete by Neural Networks," Construction Building Materials, Vol. 21, No. 2, pp. 384-494, (2005).

[19] Bilgil, A, "Estimation of Slump Value and Bingham Parameters of Fresh Concrete Mixture Composition with Artificial Neural Network Modeling," Scientific Research and Essays, Vol. 5, No. 8, pp. 1753-1765, (2012).

[20] Pala, M., Ozbay, E., Oztas, A. and Yuce, M, "Appraisal of Long-Term Effects of Fly Ash and Silica Fume on Compressive Strength of Concrete by Neural Networks," Construction Building Materials, Vol. 21, pp. 384-394, (2007).

[21] Mazloom, M, "Application of Neural Networks for Predicting the Workability of SelfCompacting Concrete," Journal of Scientific Research and Reports, Vol. 2, No. 1. pp. 429-442, (2013).

[22] Prasad, B.K., Eskandari, H. and Reddy, B.V, "Prediction of Compressive Strength of Self-Compacting Concrete and High-Performance Concrete With High Volume Fly Ash Using ANN," Construction and Building Materials, Vol. 23, pp. 117-128, (2009).

[23] Hegazy, T., Moselhi, O. and Fazio, P. "Developing Practical Neural Network Application Using Backpropagation," Journal of Microcomputers in Civil Engineering, Vol. 9, No. 2, pp. 145-159, (1994).

[24] Seleemah, A. "A Neural Network Model for Predicting Maximum Shear Capacity of Concrete Beams without Transverse Reinforcement," Canadian Journal of Civil Engineering, Vol. 32, pp. 644-657, (2005).

[25] Sodikov J. and Student, G. "Cost Estimation of Highway Projects in Developing Countries: Artificial Neural Network Approach," Journal of the Eastern Asia Society for Transportation Studies, Vol. 6, pp. 1036 - 1047. (2005) 